\title{
CONCRETE MODULAR PAVEMENTS - TYPES, ISSUES AND CHALLENGES
}

\section{AUDRIUS VAITKUS, JUDITA GRAŽULYTE்*, RITA KLEIZIENE், VIKTORAS VOROBJOVAS, OVIDIJUS ŠERNAS}

Road Research Institute, Vilnius Gediminas Technical University,

Vilnius, Lithuania

Received 5 November 2018; accepted 05 February 2019

\begin{abstract}
According to the European Asphalt Pavement Association, more than 90 per cent of the European road network is paved with asphalt. Constantly increasing traffic volume and climate change accelerate deterioration of current pavements. As a result, there arises a need to rehabilitate them prematurely. Repair and rehabilitation work lead to traffic congestion, which is one of the most significant concerns in highly trafficked roads and urban streets. Concrete modular pavements consisting of precast concrete slabs are a reasonable solution to deal with the road works since their construction, as well as repair, is time-saving. Repair works typically are implemented during a low traffic period (usually at night). A primary purpose of concrete modular pavements is heavily trafficked roads and other transport areas. This paper focuses on concrete modular pavements, their types, issues and challenges related to their design, slab fabrication and pavement construction. The conducted analysis revealed 15 different types of concrete modular pavements that differ from the techniques of slab joints and load transfer between the adjacent slabs. More than 20 issues and challenges related to the design of modular elements, slab fabrication and pavement construction were identified. Finally, the existing practice of concrete modular pavements was summarised and the gaps of scientific knowledge, as well as a need for comprehensive research, were defined.
\end{abstract}

Keywords: jointed precast concrete pavement (JPCP), modular pavement, panel, precast concrete pavement (PCP), precast prestressed concrete pavement (PPCP), slab.

* Corresponding author. E-mail: judita.grazulyte@vgtu.lt

Copyright (C) 2019 The Author(s). Published by RTU Press

This is an Open Access article distributed under the terms of the Creative Commons Attribution License (http://creativecommons.org/licenses/by/4.0/), which permits unrestricted use,

distribution, and reproduction in any medium, provided the original author and source are credited. 


\section{Introduction}

According to the European Asphalt Pavement Association, more than 90 per cent of the European road network is made of asphalt pavements. However, these pavements quickly deteriorate because they are sensitive to increasing traffic volume and climate change resulting in cracks, rutting, ravelling, potholes and other distress. The cracks and potholes are sealed during routine maintenance; however, after eight years or even less the surface course fails and has to be overlaid. An overlay improves the driving conditions, and pavement is used for the next 7-17 years until the whole pavement structure has to be rehabilitated.

Interruption of traffic by implementing repair and rehabilitation works leads to traffic congestion. A conducted study, in which more than 200000 traffic jams were analysed across 19 European countries, showed that the total economic impact of the traffic congestion would make more than 160 billion Euros by 2025 (Cookson, 2016). According to the U.S. Department of Transportation of Federal Highway Administration of Federal Transit Administration (FTA, 2013), 10 per cent of all traffic jams is related to road works. Hence, reducing road works to the minimum amount, more than 16 billion Euros will reduce the economic cost of traffic congestion over the next decade.

Concrete modular pavements also are known as precast concrete pavements (PCPs) are a reasonable solution to deal with road works since their construction is time-saving. The reason of efficient construction is slab fabrication at a manufacturer what eliminates concrete curing on-site. Typically, PCP is constructed at night (from about 8 p.m.) and in the morning (up to about 6 a.m.). Besides, precast slabs are constructed in chilly weather and during a light rain, thus, a construction season is extended. A fast construction is very significant in the east and north Europe because there is a short construction period due to cold autumn and winter seasons (less than six months). Since slabs for the concrete modular pavements are produced at a manufacturer, a high consistency of quality is ensured. In addition to this, the risk of material segregation, which is relevant to asphalt pavements during asphalt mixture transportation and laying, is eliminated. Furthermore, a higher concrete strength for PCP is typically achieved than that of the concrete used for cast-in-place concrete pavement.

Considering all the aspects mentioned above, PCP is a promising solution to reduce repair and rehabilitation works. The use of PCP leads to less traffic congestion, especially in areas with high traffic volume. Consequently, this paper focuses on the concrete modular pavements, their types, issues and challenges related to the design, fabrication and 
construction of precast slabs. This paper also reveals aspects that have to be improved or at least aspects where attention has to be paid to ensure PCP durability and sustainability.

\section{The concept of concrete modular pavements}

Concrete modular pavements typically known as PCP are pavements constructed of prefabricated concrete slabs. Typically, these slabs are fabricated at a manufacturer, later transported to the project site and installed on a prepared foundation. Precast concrete pavements are used for intermittent repairs of concrete pavements as well as for continuous construction. The rate of PCP construction in 6-8 hours is about 14-24 slabs (one slab per 20-25 min) for intermittent repairs and about 61-183 m (10-40 slabs for jointed systems) for continuous construction depending on the slab size (Smith \& Snyder, 2017; Tayabji, Ye, \& Buch, $2013 \mathrm{~b})$. It is approximately twice faster than cast-in-place repair or construction.

Intermittent repairs of concrete pavements using precast concrete slabs are conducted at specific, failed areas. Two types of intermittent repairs exist, i.e. full-slab replacement of single or several failed slabs and full-depth repairs of deteriorated joints or cracks. Independently of repair type, the repairs are always full-lane width. Intermittent repair is possible if the following aspects are fulfilled (Tayabji, Ye, \& Buch, 2013b):

- adequate support exists under the slabs;

- good load transfer is at joints;

- there is a possibility to minimise the elevation differences between the newly installed slab and the existing pavement;

- the performance of the site is acceptable in the long-term.

Under continuous construction approach, full-scale project rehabilitation (reconstruction or overlay application) of concrete pavement is conducted using PCP.

Concrete modular pavements have been investigated occasionally over the 40 years. Three types of PCP have been developed:

- precast prestressed concrete pavements (PPCPs) with transversely prestressed concrete panels;

- jointed precast concrete pavements (JPCPs) with either reinforced or prestressed concrete slabs;

- incrementally connected precast concrete pavements (ICPCPs) with either reinforced or prestressed concrete slabs.

Precast prestressed concrete pavement is characterised as precast concrete pavement in which a series of transversely prestressed panels (during manufacture of panels) is post-tensioned together in the 
longitudinal direction on the site. These post-tensioned panels form a slab. Post-tensioning leads to much longer slabs (about 19.5-99.0 $\mathrm{m}$ in length), which are effectively joint-less. Whereas, in JPCP the slabs are not post-tensioned and each slab expands and contracts independently, i.e. at every joint. These slabs are either reinforced or prestressed during manufacture. In ICPCP the deformed dowel bars are used to connect during manufacture reinforced or prestressed slabs of 4.6-9.1 $\mathrm{m}$ in length to achieve a section of 18.3-30.5 m. Active joints are constructed only between sections (series of connected slabs) (Smith \& Snyder, 2017).

Prestressed concrete slabs within a constrained pavement cross section withstand higher loads than typical concrete pavements. The reason is that some of the stress induced in PCP by traffic and climate are compensated by post-tensioning in the longitudinal direction (after panels construction) and pre-tensioning in the transverse direction (during slabs manufacture). The highest prestress because of the longitudinal post-tensioning, or transverse pre-tensioning is at the ends of the section (slab), while the lowest one is at the midsection (slab). The lowest prestress is also known as effective. This effective prestress in the concrete reduces the thickness of the slab. For example, the posttensioning of the series of panels in PPCP leads to decrease in thickness (from $5 \mathrm{~cm}$ to $10 \mathrm{~cm}$ ) in comparison to an equivalently designed cast-inplace jointed concrete pavement or JPCP (Tayabji, Ye, \& Buch, 2013b). Since thinner panels are used for PPCP, a stabilised base is preferred.

Strong and uniform slab support is key to successful PCP performance. Generally, there are three types of PCP support:

- grade-support;

- grout-support;

- piles and beams support (piles with precast crossbeams).

If grade-support is used, slabs are placed directly on the grade (base), and any remaining voids under the slabs are filled with bedding grout resulting in full support to the slabs. The existing base is used unless it has an appropriate bearing capacity and serves the longterm; otherwise, a new base is constructed typically of a dense-graded, permeable granular material or a rapid-setting lean concrete. Cementtreated or asphalt treated materials are suitable only if unlimited interruption into traffic is available.

If grout-support is used, slabs are set above base grade using levelling bolts or shims, and the gap under the slabs is filled with a high strength bedding grout. Typically, the gap is from $6.35 \mathrm{~mm}$ to $25.4 \mathrm{~mm}$. The use of urethane grout (polyurethane foam materials) eliminates a precision grading process. The grout is injected under the slabs, and it lifts the slabs to the desired position providing uniform seating of the slabs 
over the existing base. Thus, levelling bolts or shims are not necessary (Tayabji \& Ye, 2014).

If piles and beams support is used, piles and beams are constructed, and slabs are placed on them. This support type is reasonable in areas where the existing base is unstable, and all other systems are not suitable or too expensive.

A selection of the support type depends on the loading conditions of the site. If loads are low (e.g. bicycle and pedestrian paths, parking lots, low-volume roads) only grade-support is used. Otherwise, economic evaluation, based on the construction time and pavement performance, have to be done.

Precast concrete pavement slabs as well as cast-in-place concrete pavement slabs expand and contract because of daily and seasonal temperatures changes. The friction between the bottom of the slab and the surface of slab support (base) resists these movements and causes stresses in the pavement. These stresses become crucial in long, prestressed panels (PPCPs) because they reduce the compressive stress transferred to the concrete from post-tensioning. An additional treatment beneath the panels in PPCP is applied to reduce this friction. Extensive testing revealed that a single layer of polyethene sheeting results in a reasonable material regarding the requirements of constructability, effectiveness and economics (Merritt, McCullough, Burns, \& Schindler, 2000).

Typically, precast slabs are reinforced or prestressed. Reinforcement does not contribute to pavement performance as prestressing unless slabs are designed as reinforced concrete pavement. Thus, slabs are reinforced to prevent concrete from cracking due to handling and transportation. A double mat of epoxy-coated reinforcement is an appropriate solution to deal with this. At least 0.2 per cent of the slab cross-sectional area in transverse and longitudinal directions has to be reinforced. This reinforcement as well as prestressing ensures that any cracks developed over the long term of service remain tight and do not contribute to faster pavement deterioration. Prestressing is a result of pre-tensioning, which is the most common form of prestressing, or posttensioning (Smith \& Snyder, 2017; Tayabji, Ye, \& Buch, 2013b).

Precast concrete pavements are durable and lasting for 40 or more years only if slabs are correctly connected and an appropriate load transfer between adjacent slabs are ensured. In general, slabs in PCP except PPCP are connected in the same way as in jointed concrete pavements; dowel bars are used in the transverse direction, and tie bars are put in the longitudinal direction. Dowel bars are smooth, round steel bars coated of a corrosion-resistant material and ensure load transfer. They are typically placed at $300 \mathrm{~m}$. However, the middle dowel bars 
do not transfer the load at joints. Thus, 4-5 dowel bars per wheel path is considered enough (Tayabji, Ye, \& Buch, 2013b). Precast concrete pavement joints lead to smooth joint faces and are usually broader than the joints in cast-in-place jointed concrete pavement. Consequently, at the joints, there is no aggregate interlock and it is not counted on for load transfer at these joints.

\section{Concrete modular pavement types and characteristics}

\subsection{Precast prestressed concrete pavements (PPCP)}

Precast prestressed concrete pavements are similar to cast-inplace post-tensioned concrete pavements. The main difference is that PPCP has longer post-tensioned sections and expansion joints between sections. The post-tensioned sections (slabs) are formed by posttensioning together a series of panels in the longitudinal direction after construction. Each panel is prestressed in the transverse direction during manufacture. In general, three types (systems) of PPCP exist depending on the stressing location:

- central stressing;

- end stressing at the surface;

- end stressing at vertical joint face.

Each of them was developed gradually by improving the previous one. The original version is with central stressing, and for the first time it was used in Texas and later in California (Merritt, McCullough, \& Burns, 2001, 2005; Merritt, McCullough, Burns, \& Schindler, 2000). In a second one central stressing panels were eliminated and instead of them end stressing at the surface is used. This type of PPCP was used in Delaware, Missouri and Virginia projects (Merritt, Rogers, \& Rasmussen, 2008). The third version eliminated joint expansion panels and added two types of panels; end joint panels and expansion joint gap panels. This type of PPCP was used in California (I-680 project) (Mishra, French, \& Sakkal, 2013). At all base, central stressing, expansion joint, end joint and expansion joint gap panels are used in PPCP depending on its type (system).

Base panels compose the majority of the post-tensioned panels. They are used in all types of PPCP. Central stressing panels are used to posttension from the middle of the connected panels using slots fabricated in the panels. Thus the access to the end anchorage is not needed to posttension the panel. It enables a more continuous pavement construction. Central stressing panels are typically used only in the original version 
Table 1. Characteristics of Precast prestressed concrete pavement types (systems)

\begin{tabular}{|c|c|c|c|}
\hline \multirow{3}{*}{ Characteristics } & \multicolumn{3}{|c|}{ Precast prestressed concrete pavement type (system) } \\
\hline & \multirow{2}{*}{$\begin{array}{l}\text { Central } \\
\text { stressing }\end{array}$} & \multicolumn{2}{|c|}{ End stressing } \\
\hline & & at surface & at vertical joint face \\
\hline $\begin{array}{l}\text { Annual Average Daily Traffic } \\
\text { (AADT), in vehicles per day }\end{array}$ & $\begin{array}{l}\text { (27 per cent } \\
\text { of trucks) }\end{array}$ & $\begin{array}{l}9008 \\
\text { (39 per cent } \\
\text { of trucks) }\end{array}$ & $\begin{array}{l}145000-171000 \\
\text { ( } 4.7 \text { per cent of trucks) }\end{array}$ \\
\hline Design life, years & 30 & 35 & - \\
\hline $\begin{array}{l}\text { Number of equivalent single } \\
\text { axle loads (ESALs), in a million } \\
\text { ton }\end{array}$ & 127 & 163 & - \\
\hline Construction site & $\begin{array}{l}\text { IH } 35 \text { near } \\
\text { Georgetown, } \\
\text { Texas } \\
\text { Interstate 10, } \\
\text { El Monte, } \\
\text { California }\end{array}$ & $\begin{array}{l}\text { Interstate } 57 \\
\text { near Sikeston, } \\
\text { Missouri }\end{array}$ & $\begin{array}{l}\text { I-680, } \\
\text { California }\end{array}$ \\
\hline $\begin{array}{l}\text { Length of the construction } \\
\text { site, in meters }\end{array}$ & $76 ; 701$ & 305 & 12000 \\
\hline Type of panels & $\begin{array}{l}\text { base panels, } \\
\text { central stressing } \\
\text { panels, } \\
\text { expansion joint } \\
\text { panels }\end{array}$ & $\begin{array}{l}\text { base panels } \\
\text { expansion joint } \\
\text { panels }\end{array}$ & $\begin{array}{l}\text { base panels, end joint } \\
\text { panels, } \\
\text { expansion join gap } \\
\text { panels }\end{array}$ \\
\hline $\begin{array}{l}\text { Length of each section } \\
\text { of post-tensioned panels } \\
\text { (length of slab), m }\end{array}$ & $34.0-99.0$ & 76.2 & $19.5-65.8$ \\
\hline Panel width, m & $5.0-11.0$ & 11.6 & 3.6 \\
\hline Cross section & $\begin{array}{l}\text { two traffic lanes } \\
(3.7 \mathrm{~m}+3.7 \mathrm{~m}) \text {, } \\
\text { outside shoulder } \\
(2.4 \mathrm{~m}) \text {, } \\
\text { and } \\
\text { inside shoulder } \\
(1.2 \mathrm{~m}) \text {; } \\
\text { two traffic } \\
\text { lanes }(8 \mathrm{~m}) \text { and } \\
\text { shoulder }(3 \mathrm{~m})\end{array}$ & $\begin{array}{l}\text { two traffic lanes } \\
(3.7 \mathrm{~m}+3.7 \mathrm{~m}) \\
\text { inside shoulder } \\
(1.2 \mathrm{~m}) \text { and outside } \\
\text { shoulder }(3 \mathrm{~m})\end{array}$ & - \\
\hline Panel length, $m$ & $2.5-3.0$ & $3.0-4.3$ & $2.4-11.0$ \\
\hline
\end{tabular}




\begin{tabular}{|c|c|c|c|}
\hline \multirow{3}{*}{ Characteristics } & \multicolumn{3}{|c|}{ Precast prestressed concrete pavement type (system) } \\
\hline & \multirow{2}{*}{$\begin{array}{l}\text { Central } \\
\text { stressing }\end{array}$} & \multicolumn{2}{|c|}{ End stressing } \\
\hline & & at surface & at vertical joint face \\
\hline Panel thickness, cm & $20-33$ & $\begin{array}{c}14.3-27.6 \\
\text { (at least } 20 \\
\text { for the traffic } \\
\text { lanes) }\end{array}$ & $20-25$ \\
\hline Cross-slope & $\begin{array}{l}\text { uniform, } \\
\text { to the outside } \\
\text { edge } \\
\text { of the pavement }\end{array}$ & $\begin{array}{l}\text { on either side } \\
\text { of the centreline }\end{array}$ & - \\
\hline Change in cross-slope & $\begin{array}{l}\text { incorporated } \\
\text { in cross section }\end{array}$ & $\begin{array}{l}\text { incorporated } \\
\text { in cross section }\end{array}$ & - \\
\hline $\begin{array}{l}\text { Concrete strength at release, } \\
\mathrm{MPa}\end{array}$ & $24.1-27.6$ & - & - \\
\hline $\begin{array}{l}\text { Concrete strength after } 28 \\
\text { days, } \mathrm{MPa}\end{array}$ & 34.541 .4 & 34.5 & - \\
\hline $\begin{array}{l}\text { Panel-based treatment } \\
\text { to reduce friction between } \\
\text { the bottom of the panels and } \\
\text { the surface of the base (bond } \\
\text { breaker) }\end{array}$ & $\begin{array}{l}0.15 \mathrm{~mm} \\
\text { polyethene or } \\
\text { geotextile }\end{array}$ & polyethene & - \\
\hline Base & $\begin{array}{l}\text { lean concrete } \\
\text { base; } \\
\text { asphalt concrete } \\
\text { base }\end{array}$ & $\begin{array}{l}\text { permeable asphalt } \\
\text { treated base }\end{array}$ & lean concrete base \\
\hline $\begin{array}{l}\text { Installation rate for one panel, } \\
\text { min }\end{array}$ & $12-20$ & $20-30$ & 22 \\
\hline References & $\begin{array}{l}\text { Merritt, } \\
\text { McCullough, \& } \\
\text { Burns, 2001, } \\
\text { 2005; Merritt, } \\
\text { McCullough, } \\
\text { Burns, \& Schindler, } \\
2000\end{array}$ & $\begin{array}{l}\text { Merritt, Rogers, \& } \\
\text { Rasmussen, } 2008\end{array}$ & $\begin{array}{l}\text { Mishra, French, \& } \\
\text { Sakkal, } 2013\end{array}$ \\
\hline
\end{tabular}

of PPCP. Expansion joint panels are constructed at each end of posttensioned sections. They consist of two separate halves. Each half is a part of the panel on either side of the expansion joint. Expansion joint panels have dowel bars for load transfer at transverse joints and provisions for joint sealing. These panels are used in the original and the 
second version of PPCP. In the second version of PPCP, expansion joint panels also include provisions for post-tensioning using slots fabricated in the panels. End joint panels are constructed at each end of posttensioned sections only in the third version of PPCP. They have dowel bars for load transfer at transverse joints, provisions for joint sealing and provisions for post-tensioning from the face of the panel using anchorage system pockets fabricated in the end panels. Expansion joint gap panels are also used only in the third version of PPCP. Typically, it is one expansion joint gap panel (about $1.2 \mathrm{~m}$ in length), which is used between the adjacent panels to accommodate the post-tensioning. This panel has dowel bars for load transfer at transverse joints and provisions for joint sealing. If the closure of traffic is available, expansion joint gap panels are cast-in-place. The characteristics of each type (system) of PPCP are given in Table 1.

\subsection{Jointed precast concrete pavements (JPCP)}

Jointed precast concrete pavements are similar to cast-in-place jointed concrete pavements since they perform similarly. Slabs are either prestressed or reinforced. Some specific differences are as follows (Tayabji, Ye, \& Buch, 2013b):

- the slabs are installed flat; therefore, they do not exhibit construction-related curling or warping;

- the slabs are reinforced or prestressed; therefore, any in-service cracking is maintained tight;

- the slab transverse joint faces are smooth (cast surfaces); therefore, the aggregate interlock is not counted on for load transfer at these joints.

In JPCP, load transfer at transverse joints is incorporated. For this purpose, round, smooth, epoxy coated steel dowel bars or other systems (devices) are used. Typically, they are embedded in one side of the slab, while the other side has slots at locations that match the dowel bars. This scheme interconnects the adjacent slabs in the transverse direction. After interconnection, the slots and the joint gap are filled with fastsetting grout. Researchers have developed at least 11 systems based on the JPCP concept:

- Fort Miller Super-Slab System. This system was developed in the State of New York. The precast slabs (single-plane or warpedplane) are constructed on a thin layer of finely graded bedding materials placed over existing subbase. Dowel bars, tie bars and dovetail-shaped slots are cast into the bottom of each slab. This position keeps grout on the bottom and protects it from the negative effect of freezing and thawing, and de-icing chemicals. 
A special method with two grout ports in the slab over each slot is used to install non-shrink structural grout from the top of the slab to slot below. A bedding grout distribution system comprising of a half-round channels is incorporated into the bottom of each panel to fill voids under the slabs. Besides, foam gaskets are glued to the bottom of each slab to create discrete, sealed, bedding grout chambers. Fort Miller Super-Slab System is safely opened to traffic without grouting (Kohler, du Plessis, Smith, Harvey, \& Pyle, 2007; Tayabji, Ye, \& Buch, 2013a);

- Modieslab System. This system was developed in the Netherlands. The main difference from other systems is that slabs are not connected with dowel bars; they are placed on precast reinforced concrete piles with crossbeams and connected with them using prestressed anchors and sliding planes. However, slabs are also constructed on grade-support; but in this case, the load transfer between adjacent slabs has to be ensured. In slabs of the Modieslab System are constructed of a reinforced concrete layer covered with two porous concrete layers. The upper layer of porous concrete is fine-grained, while the bottom layer is coarse graded. This composition enables to reduce the tire/pavement noise at least $6 \mathrm{~dB}(\mathrm{~A})$. Slabs are manufactured upside down to guarantee a very even surface. Modieslab System may also contain a pipeline system to control the temperature of the slabs (Houbert, Huurman, van der Kooij, \& Poot, 2004, 2005; Houbert, Poot, Huurman, \& van der Kooij, 2004; Smits, 2004);

- The System used in La Guardia International Airport. This system is unique since narrow-mouth dowel slots, which are placed at the top of the slabs, are fabricated in the manufacturer and can be exposed to traffic until the next lane closure (within a day or two) what is impossible using traditional dowel slots. Furthermore, the elevation of slabs is controlled using threaded setting bolts, and a gap of 13-25 mm is kept under the slabs. This gap is later filled with fast-setting cementations grout. At this project, reinforced as well as prestressed slabs were used (Chen, Murrell, \& Larrazabal, 2004);

- Kwik Slab System. This system consists of patented Kwik joint steel couplers, which interlock reinforced precast slabs allowing reinforcement continuity throughout the length of the connection section. The pavement performs similarly to jointed reinforced concrete pavement and is an example of ICPCP. The main drawback of this system is that the lengths of the adjusted slabs are limited and expansion joints between connected sections have 
Table 2. Characteristics of jointed precast concrete pavement types (systems)

\section{Characteristic, unit}

Annual Average
Daily Traffic
(AADT),
vehicles per day

\section{Jointed precast concrete pavement type (system)}

Fort Miller Super-
Slab System

System used at La

Modieslab System Guardia International Airport

\section{Kwik Slab System}

$22000-90000$

(8.5 per cent of trucks)

\section{GP/RM}

Precast plant,

Campbell Industrial Park in Hawaii; Leoku Street Bus Stop in Waipahu, Hawaii

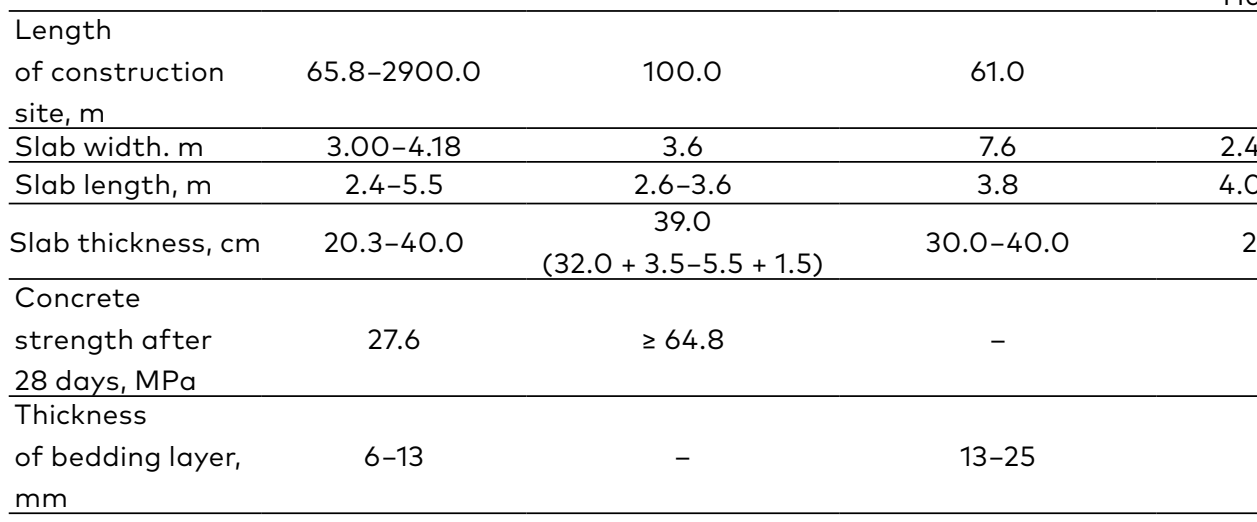

fast-setting cementations grout

cement treated

Base base; unbound granular base

Kohler, du Plessis, Houbert, Huurman, Smith, Harvey, van der Kooij, \& Poot, References \& Pyle, 2007; 2004, 2005; Houbert, Tayabji, Ye, Poot, Huurman, \& Buch, 2013a \& van der Kooij, 2004
Chen, Murrell, Tayabji, Buch,

\& Larrazabal, 2004 \& Kohler, 2008 


\section{0}

100000
(6 per cent

of trucks)
Street in Saint

Aubin-le's-Elbeuf,

France;

street in Nantes,

I-25

in Colorado

1-675

in Michigan
Route 27

in New York

France

90.0

$\begin{array}{cc}1.5-2.4 & \begin{array}{c}\text { Radius } \\ 1540 \mathrm{~mm}\end{array} \\ \begin{array}{cc}19.5-14 & (21.0) \\ 20.0-25.0 & (20.0\end{array}\end{array}$

$\frac{-}{-}$

3.6-3.7

3.7

1.8

$1.8,2.4,3.0$

(21.0)

19.0-21.6

25.4

20.3

25.4

25.4

fast-setting

flowable fill

granular material

concrete,

polyurethane

polyurethane

foam

foam

\section{structural}

excavatable

asphalt base

cement-treated

material,

granular base

cement-treated

material

Hachiya, Akamine,

Takahashi, \& Miyaji,

2001;

Nishizawa, 2008;

Tomoyuki, 1996

De Larrard,

Sedran,

\& Balay, 2013
Tayabji, Ye,

\& Buch, 2013a
Tayabji

\& Ye, 2014;

Tayabji, Ye,

\& Buch, 2013a 
to be installed. Besides, these joints are not incorporated in the Kwik Slab System. This system has been used on a limited basis in Hawaii (Tayabji, Buch, \& Kohler, 2008; Tayabji, Ye, \& Buch, 2013a);

- Japanese Systems. These systems have special load transfer systems (devices) such as sliding dowel bar, horn device and compression joint device (Hachiya, Akamine, Takahashi, \& Miyaji, 2001; Nishizawa, 2008; Tomoyuki, 1996). Compression joint device leads to more efficient load transfer between the adjacent slabs and easier replacement of failed slabs than horn device, but it is quite expensive to install. Therefore, typically a combination of horn device and compression joint device is used. It is noted that in the tunnels slabs are turned over and re-used when the surface is worn out;

- France System. This system is unique because of hexagonalshaped slabs. The joints between slabs are filled with waterproof polymeric material. In this case, slabs are mechanically independent. Otherwise, concrete connection keys are used to connect adjacent slabs and joints are filled with fine-grained sand. In this case, the pavement is built in successive lines, progressing from one edge to the other, i.e. slabs are interlocked. It enables to transfer some level of load at the joints and leads to smaller slab size (De Larrard, Sedran, \& Balay, 2013);

- Uretek System. This system is applied only in intermittent repair to lift the faulted slabs or newly placed slabs by injecting foam/grout (high-density polyurethane) to level the pavement and to ensure appropriate load transfer by "Stitch-in-time" process. This process consists of the insertion of fibreglass stitches $(0.9 \mathrm{~m}$ length, $127 \mathrm{~mm}$ wide and $6 \mathrm{~mm}$ thick) to the special narrow slots $(19 \mathrm{~mm}$ thick), which extend from one slab to the adjacent slab, and their grouting (Buch, 2007; Tayabji, Buch, \& Kohler, 2008; Tayabji, Ye, \& Buch, 2013a);

- Michigan System. This system is also only for intermittent repair and often are known as Michigan Method. Dowel bars (typically, three or four dowel bars spaced $30.5 \mathrm{~cm}$ apart from each other) are cast into the precast slab in each wheel path, while slots are made in the existing pavement at locations that match the dowel bars. Grout support on an appropriate compacted base course is used to level slabs. Slabs are placed directly on the grout (Buch, 2007; Hossain, Ozyildirim, \& Tate, 2006);

- Roman Road System. This system is only for intermittent repair and sometimes is called Roman Stone System. In this system, dowel bars are not cast into slabs and slots in the existing pavement as well as in the slabs are cut after slabs placement in the final 
position (level). A grout-support is used, i.e. polyurethane foam is injected under the placed slabs, and they are raised to the desired level (Tayabji \& Ye, 2014; Tayabji, Ye, \& Buch, 2013a);

- Pervious Precast Concrete Pavement System. This system is unique because of concrete permeability. Void content in the mixture varies from 15 per cent to 25 per cent depending on the application. Pervious precast concrete slabs are placed on a permeable base, which percolates received water from the pavement to the underlying subgrade. This system is typically used for parking lots, driveways, alleys, and sidewalks. Sometimes it is used for low-volume roads (Smith \& Snyder, 2017);

- Solar Power Generating Pavement System. This system generates power from the sun through power-generating cells placed on the precast slabs. Slabs are attached with a tube-filled, double keyway load transfer system. This pavement type is unique, and only a pilot section of $89 \mathrm{~m}$ length and $3.5 \mathrm{~m}$ wide is constructed on the bike path (Smith \& Snyder, 2017).

The characteristics of each type (system) of JPCP are given in Table 2.

It is be noted that the maximum slab dimensions in meters have to be 0.18 to 0.24 times lower than the slab thickness in centimetres and the ratio of the slab length and width has to be less than 1.5 (Smith \& Snyder, 2017).

\subsection{Incrementally connected precast concrete pavements (ICPCP)}

Incrementally connected precast concrete pavement is similar to the jointed reinforced concrete pavement with hinged joints. Typically, the slabs length varies from $4.6 \mathrm{~m}$ to $9.1 \mathrm{~m}$. These slabs in the transverse direction are connected to achieve a section from $18.3 \mathrm{~m}$ to $30.5 \mathrm{~m}$ long. The slabs are connected with deformed dowel bars. They lock the connected joint, enable the load transfer across joints and lead to narrower expansion joints between connected slabs. An active sealed joint is provided between connected slabs. Both, reinforced and prestressed slabs are used, and the thickness varies from $25.4 \mathrm{~cm}$ to $35.6 \mathrm{~cm}$ and from $20.3 \mathrm{~cm}$ to $25.4 \mathrm{~cm}$, respectively (Tayabji \& Ye, 2014; Tayabji, Ye, \& Buch, 2013a).

In general, the usage of ICPCP results in fewer active joints and narrower expansion joints. The main advantage of ICPCP over jointed reinforced concrete pavement with hinged joints is that the intermediate joints are doweled, and the load transfer at the joints does not depend on aggregate interlock (Tayabji, Ye, \& Buch, 2013a). 


\subsection{Discussion}

The analysis of PCP revealed that all three types (PPCP, JPCP and ICPCP) are used independently of AADT as well as ESALs. It is highlighted that PCP systems successfully perform in highly trafficked areas. In some projects, the ESALs were more than 100-150 million for the design life of 30-35 years.

The main differences between PPCP, JPCP and ICPCP are:

- slabs connection method/technology;

- the distance between active (expansion) joints;

- dimensions of slabs.

In PPCP and ICPCP series of panels/slabs are connected to the sections, and within these sections, panels/slabs are effectively jointless, while in JPCP each slab contracts and expands independently, i.e. at every joint. In PPCP panels are post-tensioned to achieve a section (slab) from $19.5 \mathrm{~m}$ to $99.0 \mathrm{~m}$ in length whereas in ICPCP deformed dowel bars are used (section length varies from $18.3 \mathrm{~m}$ to $30.5 \mathrm{~m}$ ). Panels for PPCP are typically fabricated in full width of all traffic lanes and shoulders (if the shoulder is necessary) and is about $2.5-4.3 \mathrm{~m}$ in length. The width of the slab in JPCP is equal to the width of one traffic lane, and the length varies from $1.8 \mathrm{~m}$ to $5.5 \mathrm{~m}$. The thickness of the slabs are similar (20-30 cm) independently of PCP type and system except ModieSlab System and System used in La Guardia International Airport where the thickness of the slab is more than $35 \mathrm{~cm}$. Slabs of Fort Miller Super-Slab System sometimes is also thicker than $35 \mathrm{~cm}$. However, in all cases, the thickness of slabs is equal to or smaller than $40 \mathrm{~cm}$. In general, it strongly depends on ESALs and either the slabs are prestressed or not.

Typically, PCP is constructed of rectangular slabs. However, France System uses hexagonal-shaped slabs. Non-rectangular slabs are more visually attractive. Thus they are a desirable solution in urban areas, e.g. for bicycle and pedestrian paths.

In PPCP a bond breaker to reduce friction between the bottom of the panels and the surface of the base course is used. Polyethene or geotextile is assumed as a good bond breaker. Meanwhile in JPCP and ICPCP a bedding layer in a thickness of $6-30 \mathrm{~mm}$ is constructed to ensure uniform support for slabs. The bedding layer may construct of fast-setting cementations grout, polyurethane foam, stone dust, washed concrete sand and other granular materials.

The analysis of JPCP revealed that in the market exist more than 11 systems of PCP created based on JPCP concept. The main differences among them are the techniques of slab connection and load transfer between the adjacent slabs. So many different systems show challenges related to slabs connection and efficient load transfer. The shape 
(rectangular or narrow mouth) and position (in the top or bottom of the slabs) of dowel slots, as well as individual load transfer devices, directly affect the construction time of JPCP, exposure to traffic without grouting and pavement performance.

PPCP, ICPCP and most systems of JPCP are used for both intermittent repair and continuous construction. Uretek System, Michigan System and Roman Road System are those systems, which have been developed only for intermittent repair, i.e. full-slab replacement of single or several failed slabs and full-depth repairs of deteriorated joints or cracks.

\section{Issues and challenges regarding concrete modular pavements}

Precast concrete pavements are an innovative solution to construct or repair roads rapidly, and it becomes vital for highly trafficked and congested areas. However, the performance of PCP strongly depends on many factors such as adjustment/connection of slabs, load transfer between adjacent slabs, base support, and concrete properties. Thus, all these aspects have to be considered during pavement design, and the best solutions for the individual case have to be selected to construct durable and sustainable pavement. Precast concrete pavements are designed using the same methods and techniques as cast-in-place concrete pavements. More sophisticated design procedures that assess the advantages of slabs fabrication at a manufacturer and different techniques for load transfer between adjacent slabs (incorporating the shape and position of dowel slots) could give higher economic efficiency. Besides, properties of concrete mixtures could also be significantly improved by using additives and innovative materials (e.g. synthetic zeolite admixture, basalt polymers, and steel fibres) (Girskas, Nagrockienė, \& Skripkiūnas, 2016; Gribniak, Arnautov, Kaklauskas, Tamulènas, Timinskas, \& Sokolov, 2015; Meškeinas, Gribniak, Kaklauskas, Sokolov, Gudonis, \& Rimkus, 2017). The analysis of existing practice in precast slabs design, fabrication, PCPs construction and performance revealed the main issues and challenges, which have to be addressed to future researches and projects. The most important of them are discussed below.

\subsection{Slab fabrication}

Slab casting time. Climatic conditions have to be evaluated and an appropriate time has to be selected. Otherwise, the heat of hydration is added or curing time is significantly reduced at too hot or too 
cold ambient temperatures, respectively. In some cases, to select an appropriate time is an issue since additional works such as form heating or cooling is needed (Merritt, McCullough, \& Burns, 2001; Mishra, French, \& Sakkal, 2013).

Slabs curing conditions. If slabs are steam or heat cured under cold climates, thermal shock is likely to occur leading to cracking. Control of the cooling regime during curing helps to avoid this (Merritt, Rogers, \& Rasmussen, 2008; Mishra, French, \& Sakkal, 2013; Tayabji, Ye, \& Buch, 2013a).

Slab squareness. It was observed that any deviation of squareness (even less than the allowed tolerance $\pm 6.35 \mathrm{~mm}$ ) leads to centreline deviation of the road and a non-uniform joint. Besides, it results in stress concentration at the corners of the panels in PPCP during posttensioning in the longitudinal direction. Thus, stricter tolerances for slab dimensions have to be selected, especially for PPCP (Merritt, McCullough, \& Burns, 2001; Smith \& Snyder, 2017).

Slab change in cross-slope (curved, non-planar or warped slabs). Precast concrete pavement construction at curves is a challenge since slabs have to be warped, i.e. the change in cross-slope has to be incorporated in the fabrication. Thus, a unique precasting form has to be prepared, and often this form cannot be adapted to another project. As a result, the cost of slabs production significantly increases (Merritt, McCullough, \& Burns, 2001, 2005; Merritt, McCullough, Burns, \& Schindler, 2000; Merritt, Rogers, \& Rasmussen, 2008; Smith \& Snyder, 2017).

Slab stacking. Slabs have to be stacked individually until their temperature reaches ambient temperature. Too early stacking, i.e. if slabs are still cooling, leads to cracking (Merritt, Rogers, \& Rasmussen, 2008; Mishra, French, \& Sakkal, 2013; Tayabji, Ye, \& Buch, 2013a).

Wedging action (correct dimensions of keyways). Joints do not close completely if keyway dimensions are not strictly controlled and a wedging action along the nose of the keyway occurs. Keyway dimensions have to ensure full contact between the top and bottom of keyways. Besides, a slight chamfer may be included on the bottom of the keyways. It will lead to easier removal from the forms and prevent keyways from corner breaking (Merritt, McCullough, \& Burns, 2001).

Bonding of the joint slabs. Generally, expansion joints consist of two halves of the joint slabs. Both of them are produced at a manufacturer. These two halves bond together, therefore, a heavy application of bond breaking material (grease or paint) has to be applied, or a bond breaker such as plastic sheeting or Styrofoam have to be included between the two halves (Merritt, Rogers, \& Rasmussen, 2008).

Ice in the post-tensioning ducts. The temporarily plugging of the posttensioning ducts in the panels for PPCP during the steam curing leads to 
ice formation in the ducts and cause problems with post-tensioning. As a result, compressed air has to be used to blow any water or other debris out of the ducts before plugging them at a manufacturer and if possible at the project site before installing them. It is essential in areas with cold climate (Merritt, Rogers, \& Rasmussen, 2008).

The shape of blockouts (pockets). It was observed that squared corners on the blockouts (pockets) in the PPCP lead to longitudinal cracking. These cracks continue from the blockouts (pockets) and are similar to hairlines. Thus, the rounding of blockouts (pockets) has to be considered. A minimum radius of 13-25 mm was recommended (Merritt, Rogers, \& Rasmussen, 2008).

Recharging. The steady growth in the use of electric vehicles requires less time-consuming approaches to charging. Charging while the vehicle is in motion is a promising method because there is no need to park a vehicle for charging and leads to the smaller vehicle battery. However, it is an issue for slab fabrication since slabs have to be equipped with coils, which create magnetic fields when charged with electricity and these magnetic fields have to be inductively transferred to the vehicle battery (Smith \& Snyder, 2017).

\subsection{Pavement construction}

Work planning. Inappropriately planned works lead to pavement construction and performance problems. All works (slabs delivery, lifting, landing, post-tensioning) have to be planned in that manner that post-tensioning in PPCP is applied before the final set of the epoxy used to bond the slabs together. Otherwise, the temporary post-tensioning strands have to be stressed and locked off at the end of the day works to provide a clamping force as the epoxy sets and reduce the possibility of any transverse cracking. If it is not fulfilled, spalling occurs during final post-tensioning (Merritt, Rogers, \& Rasmussen, 2008). In JPCP all works have to be planned in that manner, that pavement is opened to traffic only when dowel slots are grouted. Pavement opening to traffic before grouting of the dowel slots is allowable only if past practice and researches have shown that it will not cause cracking (Tayabji, Ye, \& Buch, 2013a).

Ruts and other permanent deformations in the base course. The crane, which lifts and lands the slabs, leaves ruts or other permanent deformations in the base if it is not adequately firm or well compacted. Thus, the crane during slab construction has not to be located on the base course. Otherwise, contact pressure under the crane has been determined, and additional actions to distribute the weight of the crane have to be taken. Besides, a granular base course has to be well 
compacted considering the moisture content of granular material. If the moisture content is not controlled during compaction, even after the final compaction the base course will be poorly compacted, and deep footprints will be observed (Merritt, McCullough, \& Burns, 2001; Merritt, Rogers, \& Rasmussen, 2008; Tayabji, Ye, \& Buch, 2013a).

Uniform support (base course and bedding layer). Base course and bedding layer have to be well constructed with uniform and smooth surface; otherwise, there is not a full contact between slabs and base course or bedding layer. Furthermore, material properties of the base course and bedding layer have to be considered especially for pervious PCPs to avoid material percolating into the subgrade. If it happens, slabs lose uniform support, and the purpose of the pervious pavement is defeated. If slabs do not have uniform support, they perform poorly and deteriorate faster than it was designed (Smith \& Snyder, 2017).

Slab lifting. Lifting devices that are time-consuming in terms of their preparation and patching are not desirable since the placement of slabs is slowed down. Thus, screw-type devices or other lifting devices that are quickly attached and removed have to be used to lift the slabs (Merritt, McCullough, \& Burns, 2001).

Slab alignment. Slabs have to be constructed in such a way that the centreline of the precast slabs meets the exact centerline of the road. In addition to this, slabs have to be well aligned in a transverse direction. Any misalignment of slabs results in difficulties in pushing the strands through the ducts in PPCP and cause friction between the ducts and the strands. If slab alignment is not possible and misalignment is relatively small, the slabs have to be offset, and larger diameter or flat multi-strand ducts have to be used. The usage of shims to correct alignment is not allowed since gaps between the slabs will lead to uneven distribution of the longitudinal prestress (Merritt, McCullough, \& Burns, 2001; Merritt, Rogers, \& Rasmussen, 2008; Tayabji, Ye, \& Buch, 2013a).

Load transfer at joints. An adequate load transfer at the joints has to be ensured by correctly selecting the PCP system and accurately constructing joints or developing new approaches on how to transfer the load between adjacent slabs efficiently. Greater than 90 per cent load transfer is necessary for continuous application in highly trafficked roads (Tayabji, Ye, \& Buch, 2013a).

Faulting. The wrong type of joints causes it. In some projects, faulting appeared in the shoulders because the butt joints were used instead of keyway joints, which were used for the traffic lanes. Therefore, the same type of joints has to be used across the full width of the road. If it is not possible and keyways are used for the traffic lanes, the dowels and pins have to be used to help to ensure vertical alignment in regions without keyways (Merritt, Rogers, \& Rasmussen, 2008). 
Grout leakage. Grout leaks from the tendons between panels even though foam or rubber gaskets and epoxy coating are used at intermediate joints in PPCP. Thus, an advanced approach to connect tendons across the panel joint or improvement of grout has to be developed to prevent grout leakage (Merritt, McCullough, \& Burns, 2001; Merritt, Rogers, \& Rasmussen, 2008; Mishra, French, \& Sakkal, 2013; Tayabji, Ye, \& Buch, 2013a). In pervious PCPs, grout leakage is also an issue because it penetrates the permeable base. Techniques on how to prevent leakage of grout injected in the bottom slot have to be developed as well (Smith \& Snyder, 2017).

Compliance of concrete properties at the site with the properties in the laboratory. It is crucial to ensure the same concrete properties at the site, as they were determined in the laboratory; otherwise, pavement performs unexpectedly. For example, higher concrete strength at the site than it was designed sometimes seems preferable, but higher modulus of elasticity leads to significantly higher strains and stresses, particularly at early ages, and thus is not desirable (Merritt, Rogers, \& Rasmussen, 2008).

Consistency of concrete properties and workability. Concrete properties, as well as workability, differ within the different time of production. It is essential to ensure the same concrete properties and workability independently of production time. A consistency of workability is likely to become an issue if some additives such as fibres are used (Mishra, French, \& Sakkal, 2013).

\section{Conclusions}

Precast concrete pavements have been investigated occasionally over the 40 years. They became one of the most important research objects in the XXI century. During that period, three different types of precast concrete pavement have been developed (precast prestressed concrete pavement, jointed precast concrete pavement and incrementally connected precast concrete pavement) for intermittent repairs as well as continuous construction. Each of them has specific techniques for slab connection, the different distance between active (expansion) joints and different dimensions of slabs. Three systems of precast concrete pavement nowadays existing in the market have been created based on precast prestressed concrete pavement concept and 11 systems - based on jointed precast concrete pavement concept.

Annual Average Daily Traffic as well as the ESALs do not influence the selection of precast concrete pavement type and successfully perform in highly trafficked areas. In some projects, the ESALs were more than 
100-150 million for a design life of 30-35 years and pavements still successfully withstood induced stresses.

The analysis of precast concrete pavement showed the following peculiarities of each type regarding slab dimensions, reinforcement and connection:

- precast prestressed concrete pavement - panels are fabricated in full width of all traffic lanes and shoulders (if they are necessary), and the length varies from $2.5 \mathrm{~m}$ to $4.3 \mathrm{~m}$. They are transversely prestressed during manufacture and post-tensioned on the site to achieve a section (slab) from $19.5 \mathrm{~m}$ to $99.0 \mathrm{~m}$ in length;

- jointed precast concrete pavement - slabs are fabricated equal to the width of one traffic lane, and the length varies from $1.8 \mathrm{~m}$ to $5.5 \mathrm{~m}$. They are either reinforced or prestressed during manufacture. Typically, different systems of dowel bars and slots are used to connect adjacent slabs. Each slab contracts and expands independently, i.e. at every joint;

- incrementally connected precast concrete pavements - slabs are fabricated equal to the width of one traffic lane, and the length varies from $4.6 \mathrm{~m}$ to $9.1 \mathrm{~m}$. They are either reinforced or prestressed during manufacture. Deformed dowel bars are used to connect a series of slabs to achieve a section from $18.3 \mathrm{~m}$ to $30.5 \mathrm{~m}$.

The thickness of the slabs strongly depends on ESALs and presence of reinforcement (prestressed or not). Typically, the thickness of the slab is $20-30 \mathrm{~cm}$ independently of precast concrete pavement type. In some cases, especially in airports, slabs are thicker than $30 \mathrm{~cm}$. However, in all cases, the thickness of slabs is equal to or less than $40 \mathrm{~cm}$.

The analysis of existing practice in precast concrete pavement revealed more than 20 issues and challenges related to slab fabrication and pavement construction that have to be addressed in future research. The most important of them are fabrication of curved (warped) slabs, slabs with inductive charging option, assurance of uniform and even support under the slabs, quick attachment of the lifting devices and their removal so that the slab is not damaged, systems and approaches for slabs connection (joints) that ensure an efficient (more than 90 per cent) load transfer at joints, grout leakage from the tendons in precast prestressed concrete pavement and from bottom slot in pervious precast concrete pavements, compliance of concrete properties at the site with the properties in the laboratory and consistency of concrete properties and workability within different time of production (especially if some additives such as fibres are used). 
Future researches and projects have focused on the development of innovative concrete mixtures having superior characteristics such as very high compressive or flexural strength, surface texture, which reduces noise induced by interaction between tire and pavement, low rolling resistance to reduce the emission of carbon dioxide and others, which deal with social and economic aspects. Improved concrete mixtures will lead to thinner slabs with better surface performance and structural durability.

\section{Funding}

This research is part of "Modular Pavements" project funded by the European Regional Development Fund according to the supported activity "Research Projects Implemented by World-class Researcher Groups" under Measure No. 01.2.2-LMT-K-718.

\section{REFERENCES}

Buch, N. (2007). Precast Concrete Panel Systems for Full-Depth Pavement Repairs. Field Trials (No. FHWA-HIF-07-019)

Chen, Y. S., Murrell, S. D., \& Larrazabal, E. (2004). Precast Concrete (PC) Pavement Tests on Taxiway DD at Laguardia Airport. In Airfield Pavements: Challenges and New Technologies (pp. 447-483). https://doi.org/10.1061/40711(141)30

Cookson, G. (2016). Europe's Traffic Hotspots. Measuring the impact of congestion in Europe.

De Larrard, F., Sedran, T., \& Balay, J. M. (2013). Removable urban pavements: an innovative, sustainable technology. International Journal of Pavement Engineering, 14(1), 1-11. https://doi.org/10.1080/10298436.2011.634912

Federal Transit Administration (FDA) (2013). Status of the Nation's Highways, Bridges and Transit: Conditions \& Performance.

Girskas, G., Nagrockienè, D., \& Skripkiūnas, G. (2016). The effect of synthetic zeolite admixture on the durability of concrete paving blocks. The Baltic Journal of Road and Bridge Engineering, 11(3), 215-221. https://doi.org/10.3846/bjrbe.2016.25

Gribniak, V., Arnautov, A. K., Kaklauskas, G., Tamulènas, V., Timinskas, E., \& Sokolov, A. (2015). Investigation on application of basalt materials as reinforcement for flexural elements of concrete bridges. The Baltic Journal of Road and Bridge Engineering, 10(3), 201-206. https://doi.org/10.3846/bjrbe.2015.25

Hachiya, Y., Akamine, F., Takahashi, O., \& Miyaji, Y. (2001). Rapid repair with precast prestressed concrete slab pavements using compression joint system. In Seventh International Conference on Concrete Pavements. The Use of Concrete in Developing Long-Lasting Pavement Solutions for the 21st Century. International Society for Concrete Pavements (Vol. 2). 
Hossain, M. S., Ozyildirim, H. C., \& Tate, T. R. (2006). Evaluation of precast patches on US 60 near the New Kent and James City County line (No. VTRC 06-R22). Virginia Transportation Research Council.

Houbert, L. J. M., Huurman, M., van der Kooij, J., \& Poot, S. (2004, September). APT Testing and 3D Finite Element Analysis of 'Modieslab'Modular Pavement Structures. In 2nd International Conference on Accelerated Pavement Testing, Minneapolis, MN, USA.

Houbert, L. J. M., Poot, S., Huurman, M., \& van der Kooij, J. (2004). Developments on the ModieSlab Innovative Concrete Pavement Concept. In 9th International Symposium on Concrete Roads, Istanbul, Turkey, 4-7 April 2004.

Houbert, L. J., Huurman, M., van der Kooij, J., \& Poot, S. (2005). Modieslab Innovative Concrete Pavement Structure: From Idea through Research to Implementation. In Eighth International Conference on Concrete Pavements American Association of State Highway and Transportation Officials (AASHTO), American Concrete Pavement Association, Cement Association of Canada, Colorado Department of Transportation Concrete Reinforcing Steel Institute, Federal Highway Administration, Portland Cement Association, Purdue University, Transportation Research Board.

Kohler, E., du Plessis, L., Smith, P. J., Harvey, J., \& Pyle, T. (2007, November). Precast concrete pavements and results of accelerated traffic load test. In International Conference on Optimizing Paving Concrete Mixtures and Accelerated Concrete Pavement Construction and Rehabilitation. Atlanta, Georgia.

Merritt, D. K., McCullough, B. F., \& Burns, N. H. (2001). Construction and preliminary monitoring of the Georgetown, Texas precast prestressed concrete pavement. Center for Transportation Research, the University of Texas at Austin.

Merritt, D. K., McCullough, B. F., \& Burns, N. H. (2005). Design-Construction of a Precast, Prestressed Concrete Pavement for Interstate 10, El Monte, California. PCI Journal, 50(2), 18-27. https://doi.org/10.15554/pcij.03012005.18.27

Merritt, D. K., McCullough, B. F., Burns, N. H., \& Schindler, A. K. (2000). The Feasibility of Using Precast Concrete Panels to Expedite Highway Pavement Construction. Report No. FHWA/TX-01-1517-1. Austin, Texas.

Merritt, D. K., Rogers, R. B., \& Rasmussen, R. 0. (2008). Construction of a Precast Prestressed Concrete Pavement Demonstration Project on Interstate 57 near Sikeston, Missouri. Federal Highway Administration.

Meškėnas, A., Gribniak, V., Kaklauskas, G., Sokolov, A., Gudonis, E., \& Rimkus, A. (2017). Experimental investigation of cracking behaviour of concrete beams reinforced with steel fibres produced in Lithuania. The Baltic Journal of Road and Bridge Engineering, 12(2), 82-87. https://doi.org/10.3846/bjrbe.2017.10

Mishra, T., French, P., \& Sakkal, Z. (2013). Engineering a better road: Use of two-way prestressed, precast concrete pavement for rapid rehabilitation. PCI Journal, 58(1), 129-141. https://doi.org/10.15554/pcij.01012013.129.141

Nishizawa, T. (2008). Japanese Experience of Precast Concrete Pavement. In 9th International Conference on Concrete Pavements, San Francisco California, USA, 17-21 August 2008. 
Smith, P., \& Snyder, M. B. (2017). Manual for Jointed Precast Concrete Pavement.

Smits, F. (2004). ModieSlab: Innovative Prefabricated Modular Concrete Slab for Concrete Roads and Airfields. In 9th International Symposium on Concrete Roads, Istanbul, Turkey, 4-7 April 2004.

Tayabji, S., \& Ye, D. (2014). Precast Concrete Pavement Innovation, Performance and Best Practices. In 12th International Symposium on Concrete Roads, Prague, Czech Republic, 23-26 September 2014 (pp. 1-16).

Tayabji, S., Buch, N., \& Kohler, E. (2008). Precast Concrete Pavements: Current Technology and Future Directions. In 9th International Conference on Concrete Pavements, International Society for Concrete Pavements, Federal Highway Administration, American Concrete Pavement Association.

Tayabji, S., Ye, D., \& Buch, N. (2013a). Precast concrete pavement technology. Transportation Research Board.

Tayabji, S., Ye, D., \& Buch, N. (2013b). Precast concrete pavements: Technology overview and technical considerations. PCI Journal, 58(1), 112-128.

https://doi.org/10.15554/pcij.01012013.112.128

Tomoyuki, T. (1996). Patent No. 5586834. USA.
Audrius Vaitkus, Judita Gražulytè, Rita Kleizienè, Viktoras Vorobjovas, Ovidijus Šernas

Concrete Modular Pavements -

Types, Issues and Challenges 